\title{
Game Theory-based Economic Analysis and Incentive Mechanism of Complex Geothermal Energy
}

$\mathrm{Hao} \mathrm{Wu}$

Department of National Defense Economy, Army Logistics University of PLA, Chongqing 401331, China

Corresponding Author Email: 990366193@qq.com

https://doi.org/10.18280/ijht.370207

Received: 28 November 2018

Accepted: 22 February 2019

\section{Keywords:}

geothermal energy, energy market, Game theory, economy, economic incentive system

\begin{abstract}
Geothermal energy is a key clean energy in China that can be applied in heating, hot springs and aquaculture. However, the recovery of geothermal energy depends heavily on electricity, the market is narrow and the initial investment is very high. Focusing on the geothermal energy development in Beijing, China, this paper applies the game theory to analyze the economy of complex geothermal energy and designs the economic incentive system for geothermal energy. Specifically, the energy analysis and thermoeconomic analysis methods were designed for geothermal energy system, in the light of the thermodynamic laws. The investment cost, specific negative entropy cost and comparable irreversible cost of geothermal energy recovery were examined in details, revealing that the recovery of geothermal resources needs the least investment in Miyun, Haidian and Fangshan, and that Changping has the smallest relative cost difference and energy economics factor in Beijing. In addition, economic incentive measures were put forward, including both tax incentive and financial subsidy. The research findings lay the theoretical basis for expanding the development and utilization of geothermal energy.
\end{abstract}

\section{INTRODUCTION}

Energy is of strategic importance in the national economy. Out of the various energy sources, the geothermal energy provides a recyclable natural resource, without breaking the dynamic equilibrium of resources. This renewable energy source is defined as the thermal energy stored in underground rock and soil mass and groundwater within a depth that can be exploited under the current technical and economic conditions. As an integral part of the thermal energy on Earth, geothermal energy enjoys good sustainability, easy access, high efficiency and low cost. As a result, geothermal energy has increased rapidly in scale in recent years, taking up a growing proportion in the energy structure [1-2].

Like any other energy system, the geothermal energy system has multiple ways to convert heat into power. The thermal energy plays a critical role in the conversion process [3-4]. Through the conversion, the total amount of energy remains unchanged, yet the amount of usable energy continues to decrease. To fully understand the cost-incurring thermodynamic process, it is necessary to analyze the economy of the power generation procedure [5].

With the recent boom of clean energy, complex geothermal energy is being vigorously promoted and developed as a novel type of self-thermal resource [6]. The complex geothermal energy can mitigate the pressure of energy security, reduce air pollution and suppress greenhouse gas emission [7]. The economic analysis of complex thermal energy needs to consider both physical environment (e.g. temperature, pressure and chemical potential) and economic environment (price, cost and profit), as well as the first and second laws of thermodynamics [8].

Focusing on the geothermal energy development in Beijing, China, this paper employs the game theory to analyze the economy of complex geothermal energy, and designs an economic incentive system for geothermal energy. The economic incentive system pursues the sustainable development of renewable energy, and solves the bottleneck of the development of geothermal energy [9].

\section{DEVELOPMENT OF COMPLEX GEOTHERMAL ENERGY AND THERMOECONOMIC MODELLING}

\subsection{Development of complex geothermal energy}

Geothermal energy is usually extracted from geothermal water, which could reach up to $90^{\circ} \mathrm{C}$. This extraction method has limited sustainability. The extracted energy is mainly used in heating, hot springs and aquaculture [10]. Beijing boasts a huge potential of geothermal resources. If geothermal heat pumps are buried in places with suitable geological conditions, the city can acquire over 4,000 tce/h of geothermal energy at a low cost for winter heating [11]. Besides, the utilization of geothermal energy helps reduce the emission of carbon dioxide and the discharge of pollutants like dust. Through the alternating cycles of winter and summer, the resources can be naturally replenished and fully recycled [12].

Figure 1 shows the potential geothermal energy resources in all districts of Beijing. It is clear that the following districts are rich in geothermal energy: Haidian, Chaoyang, Changping and Shunyi. According to incomplete statistics, Beijing can save more than 600,000 tce through rational use of geothermal resources. 


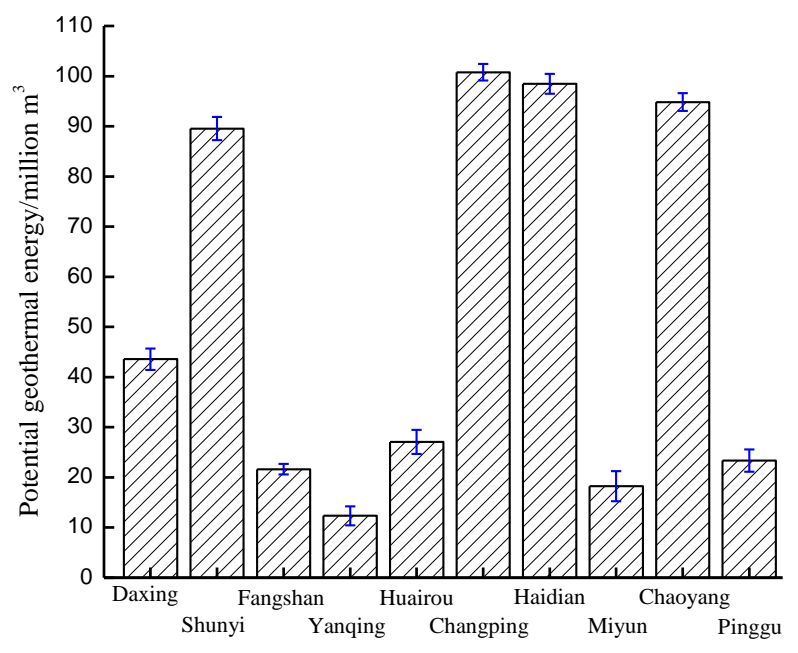

Figure 1. Potential geothermal resources in Beijing

The utilization of geothermal resources started late in China. Currently, geothermal energy only accounts for $5 \%$ of China's energy structure. Despite the late start, the application of geothermal resources is expanding rapidly [13]. With the increased popularity of geothermal energy, efforts should be made to optimize the energy structure, making it green and carbon-efficient.

\subsection{Thermoeconomic modelling}

With inputs like exploration, equipment, electricity and manpower, the economic activities of geothermal resources mainly output thermal products and services like urban heating [14]. The inputs and outputs of these activities can be evaluated by thermoeconomic analysis, which considers the material, energy and cash between the energy system and the environment as flows. Any flow entering or leaving a part of the system or environment must obey the laws of the economic environment, including the mass equilibrium, energy equilibrium and cost equilibrium. The most important index of thermoeconomic modelling is cost (energy cost and cash cost). The amount of external resources required to obtain a unit of energy flow, denoted as $\mathrm{k}$, can be computed by:

$$
\mathrm{k}=\mathrm{B} ' / \mathrm{B}
$$

where, $\mathrm{B}$ is the energy flow; $\mathrm{B}^{\prime}$ is the amount of external resources required to exploit geothermal resources.

Figure 2 illustrates the development of complex geothermal energy, the environment and the economic system. It can be seen that the energy development is supported by the environment and the economic system.

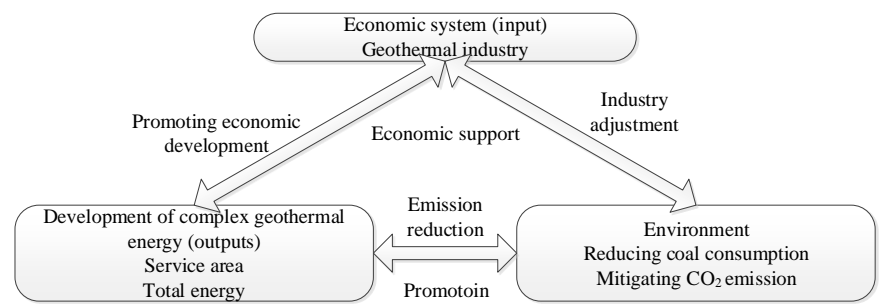

Figure 2. The development of complex geothermal energy, the environment and the economic system
According to the second law of thermodynamics, when the energy value is determined, the energy sources should be classified by the production purpose of the energy system and recovery equipment, to clearly describe the objective and efficiency of the energy system. The recovery equipment either generate or consume energy.

\section{THERMOECONOMIC ANALYSIS OF COMPLEX GEOTHERMAL ENERGY}

\subsection{Thermoeconomic cost of complex geothermal energy}

In terms of thermodynamics, the economy of complex geothermal energy is mainly reflected by energy efficiency, unit energy consumption, energy loss coefficient and energy loss rate. Nevertheless, these parameters only demonstrate thermodynamic factors of geothermal energy, failing to consider the cost factor.

In terms of economic cost, the economy of geothermal energy should be measured by the cost incurred by the recovery equipment and labor. According to the statistics released by China in 2018, the geothermal industry is highly profitable: the operating income has increased by over $40 \%$ year-on-year, and the net profit margin has surpassed $300 \%$. Moreover, the recovery of geothermal resources relies heavily on electricity. Since most electricity in China is produced in coal-fired power plants, it is safe to say that geothermal resource recovery also depends a lot on coal resources.

The thermoeconomic cost of geothermal energy development was explained by the case of Water Energy, an enterprise engaging in geothermal pump installation and maintenance and geothermal operation. The enterprise's profitability of geothermal energy development is shown in Figure 3.

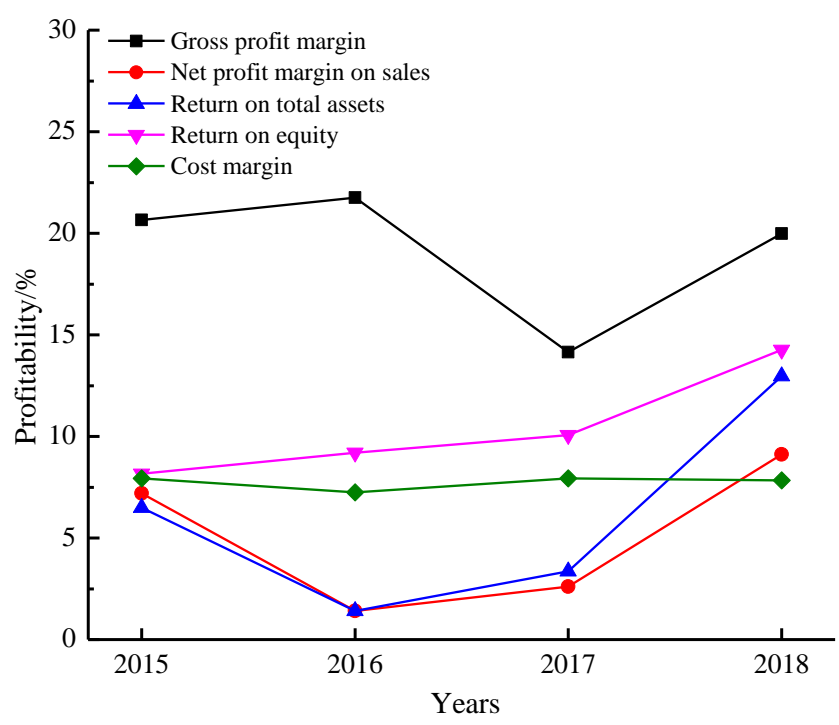

Figure 3. Profitability of geothermal energy development

As shown in Figure 3, the enterprise achieved the highest gross profit margin in 2016, but the net profit margin on sales and return on total assets were both minimum in that year. The main reason is that a huge investment was made in 2016 to overcome the difficulty in geothermal energy recovery. After that, the net profit margin on sales and return on total assets surged up from 2016 to 2017 and from 2017 to 2018. As a 
result, the return on equity and cost margin both increased year by year.

The operational capacity indices in Figure 4 show that, the receivable turnover rate increased every year, the days sales outstanding dropped yearly, and the current assets turnover rate and the total asset turnover rate both grew slowly year after year, but at slow rates.

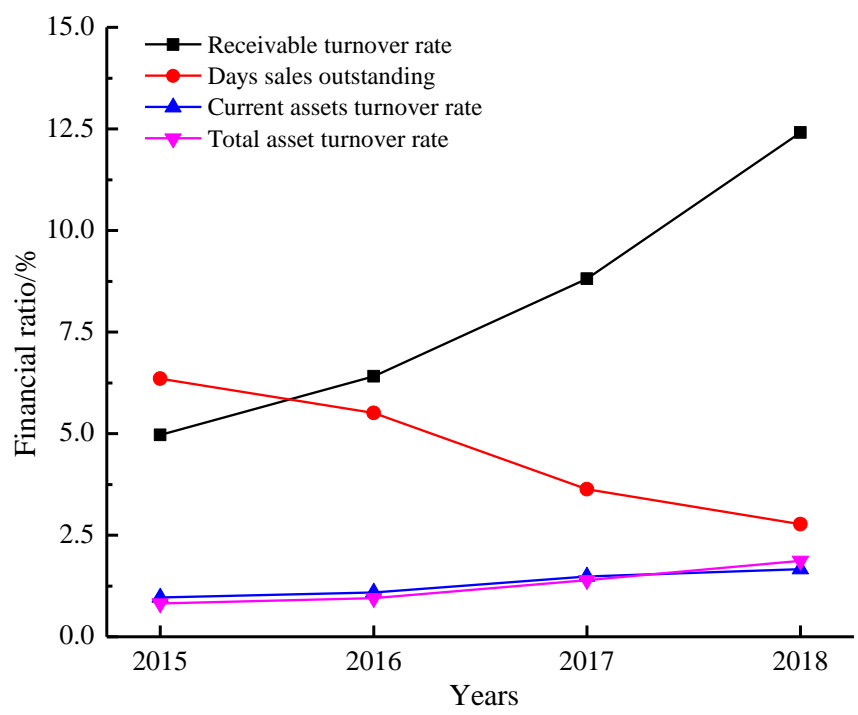

Figure 4. Operational capacity indicies for geothermal energy development

\subsection{Thermoconomic system performance evaluation of complex geothermal energy}

The energy system established by traditional energy optimization method cannot accurately reflect the shortage of energy resources. To solve the problem, the complex thermodynamics and economics can be linked up by energy cost, creating a new method called thermoeconomic system performance evaluation. This novel approach mainly targets three aspects of the energy system, namely, integrity, design and operation.

During the recovery of geothermal energy, the optimization of operation and control is an important measure to improve production technique and reduce economic cost. With the continuous development of geothermal energy, the geothermal energy system often has complex internal structures and numerous system parameters. The system cost can be optimized by mathematical optimization algorithm.

In this paper, the geothermal energy cost is optimized by mathematical optimization algorithm, considering the parameters of physical and economic environment in each district of Beijing. The average cost composition of thermoeconomics in each district is shown in Figure 5, and the relative cost difference and energy economics factor of each district is given in Figure 6.

The above figures show that the investment cost, specific negative entropy cost and comparable irreversible cost changed by different laws in different districts. The three costs were higher in Daxing than any other district. The recovery of geothermal resources needs the least investment in Miyun, Haidian and Fangshan. Changping has the smallest relative cost difference and energy economics factor in Beijing.

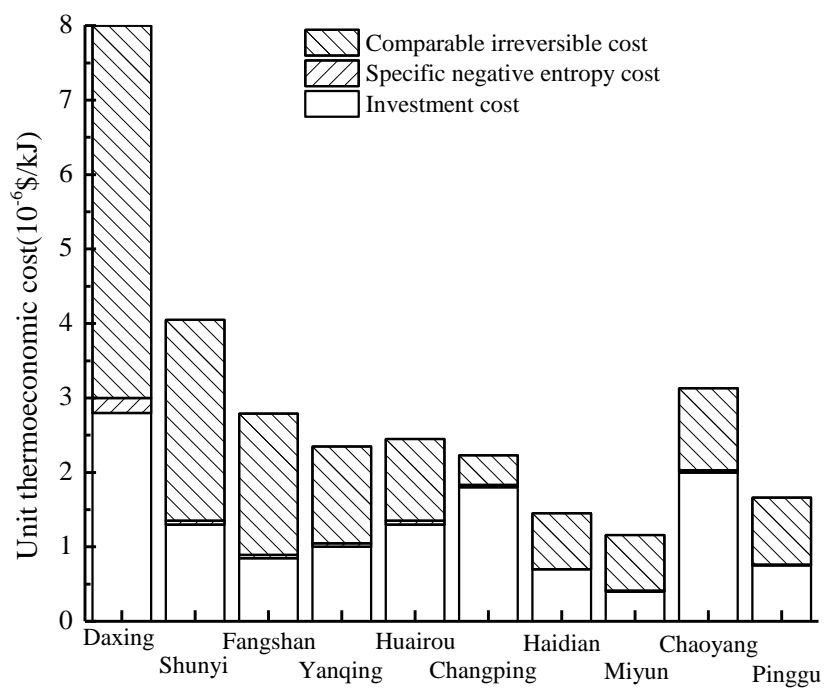

Figure 5. The average cost composition of thermoeconomis

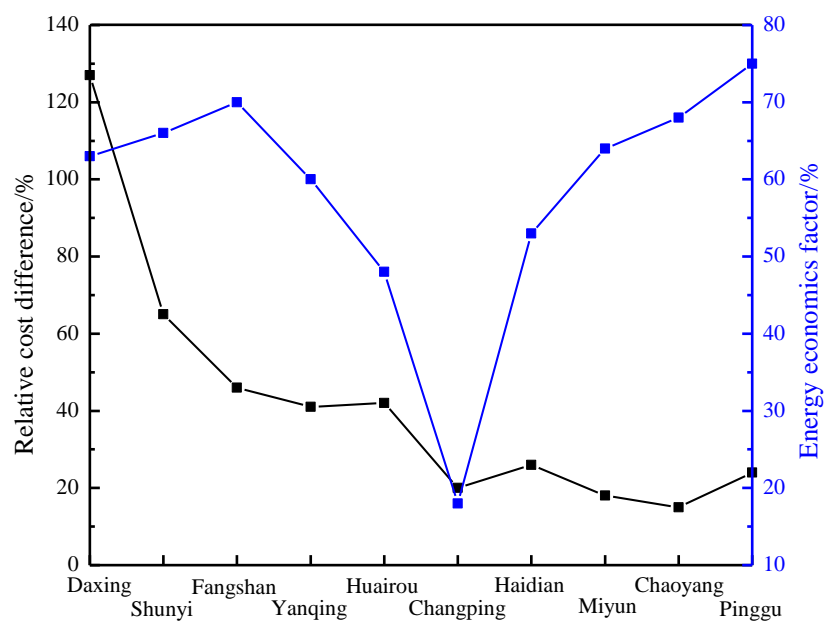

Figure 6. Relative cost difference and energy economics factor

\section{ECONOMIC INCENTIVE SYSTEM FOR COMPLEX GEOTHERMAL ENERGY}

\subsection{Tax incentive system for complex geothermal energy}

Geothermal energy has become the cleanest energy source for living and production. With the growing awareness of environmental pollution and greenhouse gas emission, the international community has started to reconstruct the energy structure and vigorously promote clean energies like geothermal energy.

In the light of game theory, the economic incentive system for geothermal energy corrects the external diseconomies of conventional energy consumption, rather than create an economic burden. With clear incentives, this system is welcomed by market players and favorable to macro-control. It is the key to solve the bottleneck of development of geothermal energy and other renewable energies. The existing economic incentive systems for energy development involve financial subsidy, tax incentive, preferential price and government procurement of renewable energies.

Among them, the tax incentives must be implemented step by step. The indirect guidance should be integrated with direct 
incentives, the encouraging measure should be coupled with punitive measure, and the all-round promotion should be supported by multi-link guidance.

Currently, the tax incentives for geothermal energy include tariff reduction, exemption of investment tax, reduction of VAT and income tax, etc. Tax incentives are a useful tool for a country to promote the development of a specific industry, and exert little impact on the total tax revenue.

The author collected the data on geothermal energy development and the input factors of different industries in Beijing from 2010 to 2018. On this basis, the tax value of geothermal energy as a percentage of the regional GDP and the service area of geothermal heating were predicted for 2019 2030. The predicted results in Figure 7 indicate that the tax value of geothermal energy will take up a growing portion of the regional GDP in the following 12 years.

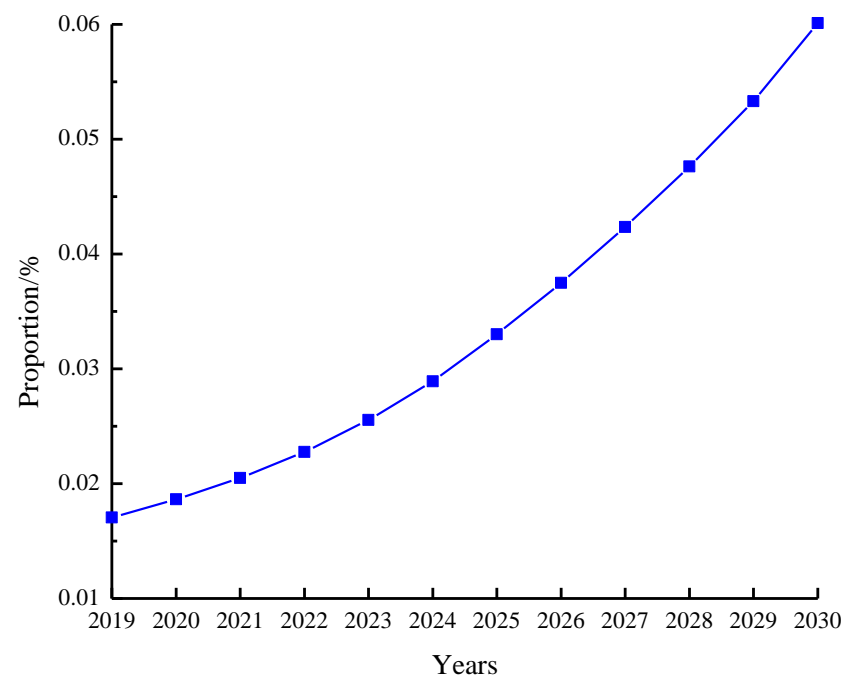

Figure 7. The tax value of geothermal energy as a percentage of the region's gross domestic product

\subsection{Financial subsidy for complex geothermal energy}

The financial subsidy is a catalyst for the application and industrialization of geothermal energy. In fact, geothermal energy is not competitive in terms of initial investment and production cost. For geothermal energy, the market is narrow, the production scale is small and the initial investment is high.

As an incentive measure, the financial subsidy generally targets investment, $\mathrm{R} \& \mathrm{D}$, output and the user. Among them, investment subsidy refers to the direct compensation for investors of geothermal energy production projects. This type of subsidy is implemented by developed countries like the US, Germany, and Japan. The user subsidy also has great significance. The user can direct use the subsidy for energy conservation and to pay for energy cost.

In addition, the financial subsidy is the most direct way for the government to stimulate the use of complex geothermal energy. This measure can greatly arouse the enthusiasm of investors.

The promotion of geothermal energy can expand the winter heating area, reduce fossil energy consumption and protect the environment. Figure 8 shows the geothermal energy heating as a percentage of the total service area.

It can be seen that geothermal energy will serve a growing proportion of heating area in the next decade. Currently, China is beefing up its financial subsidy for renewable energies like geothermal energy year by year. Unlike developed countries, the geothermal energy projects in China have not been included in the fiscal budgets and plans at all levels.

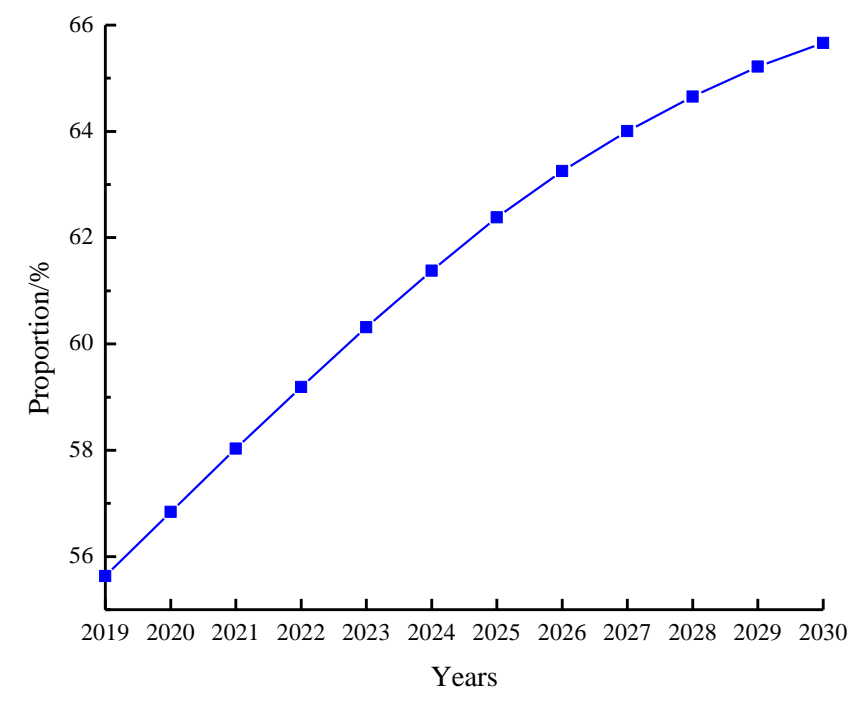

Figure 8. Geothermal energy heating as a percentage of the total service area

\section{CONCLUSIONS}

Focusing on the geothermal energy development in Beijing, China, this paper applies the game theory to analyze the economy of complex geothermal energy and designs the economic incentive system for geothermal energy. The main conclusions are as follows:

(1) With the continuous development of geothermal energy, the geothermal energy system often has complex internal structures and numerous system parameters. The system cost can be optimized by mathematical optimization algorithm. Through the optimization, it is learned that Changping has the smallest relative cost difference and energy economics factor in Beijing.

(2) The thermoeconomic system performance evaluation mainly targets three aspects of the energy system, namely, integrity, design and operation. During the recovery of geothermal energy, the optimization of operation and control is an important measure to improve production technique and reduce economic cost.

(3) In the light of game theory, the economic incentive system for geothermal energy corrects the external diseconomies of conventional energy consumption, rather than create an economic burden. With clear incentives, this system is welcomed by market players and favorable to macrocontrol.

\section{REFERENCES}

[1] Webster, A., Ayatakshi, S. (2013). The effect of fossil energy and other environmental taxes on profit incentives for change in an open economy: Evidence from the UK. Energy Policy, 61: 1422-1431. https://doi.org/10.1016/j.enpol.2013.05.016

[2] Faúndez, P. (2008). Renewable energy in a market-based economy: how to estimate its potential and choose the right incentives. Renewable Energy, 33(8): 1768-1774. 
https://doi.org/10.1016/j.renene.2007.09.017

[3] Angrisani, G., Diglio, G., Sasso, M., Calise, F., Dentice d'Accadia, M. (2016). Design of a novel geothermal heating and cooling system: Energy and economic analysis. Energy Conversion and Management, 108: 144159. https://doi.org/10.1016/j.enconman.2015.11.001

[4] Mosaffa, A.H., Mokarram, N.H., Farshi, L.G. (2017). Thermo-economic analysis of combined different orcs geothermal power plants and LNG cold energy. Geothermics, 65: 113-125. https://doi.org/10.1016/j.geothermics.2016.09.004

[5] Gemelli, A., Mancini, A., Longhi, S. (2011). GIS-based energy-economic model of low temperature geothermal resources: A case study in the Italian Marche region. Renewable Energy, 36(9): 2474-2483. https://doi.org/10.1016/j.renene.2011.02.014

[6] Buonomano, A., Calise, F., Palombo, A., Vicidomini, M. (2015). Energy and economic analysis of geothermalsolar trigeneration systems: a case study for a hotel building in ischia. Applied Energy, 138: 224-241. https://doi.org/10.1016/j.apenergy.2014.10.076

[7] Tempesti, D., Fiaschi, D. (2013). Thermo-economic assessment of a micro CHP system fuelled by geothermal and solar energy. Energy, 58: 45-51. https://doi.org/10.1016/j.energy.2013.01.058

[8] Yilmaz, C., Kanoglu, M., Bolatturk, A., Gadalla, M. (2012). Economics of hydrogen production and liquefaction by geothermal energy. International Journal of Hydrogen Energy, 37(2): 2058-2069. https://doi.org/10.1016/j.ijhydene.2011.06.037
[9] Akhmadullin, I., Tyagi, M. (2017). Numerical analysis of downhole heat exchanger designed for geothermal energy production. Geothermal Energy, 5(1): 13-13. https://doi.org/10.1186/s40517-017-0071-2

[10] Astolfi, M., Xodo, L., Romano, M. C., Macchi, E. (2011). Technical and economical analysis of a solar-geothermal hybrid plant based on an organic Rankine cycle. Geothermics, $\quad 40(1)$ : 58-68. https://doi.org/10.1016/j.geothermics.2010.09.009

[11] Rubio-Maya, C., Edgar, P.M., Romero, C.E., Ambriz Díaz, V.M., Pacheco-Ibarra, J.J. (2016). Technoeconomic assessment for the integration into a multiproduct plant based on cascade utilization of geothermal energy. Applied Thermal Engineering, 108: 84-92. https://doi.org/10.1016/j.applthermaleng.2016.07.108

[12] Feng, R., Che, S., Wang, X., Wan, J. (2014). An incentive mechanism based on game theory for trust management. Security and Communication Networks, 7(12): 2318-2325. https://doi.org/10.1002/sec.941

[13] Dubina, I.N., Oskorbin, N.M. (2015). Game-theoretic models of incentive and control strategies in social and economic systems. Cybernetics and Systems, 46(5): 303319. https://doi.org/10.1080/01969722.2015.1007756

[14] Schüppler, S., Fleuchaus, P., Blum, P. (2019). Technoeconomic and environmental analysis of an aquifer thermal energy storage (ATES) in Germany. Geothermal Energy, 7(1): 1-24. https://doi.org/10.1186/s40517-0190127-6 